
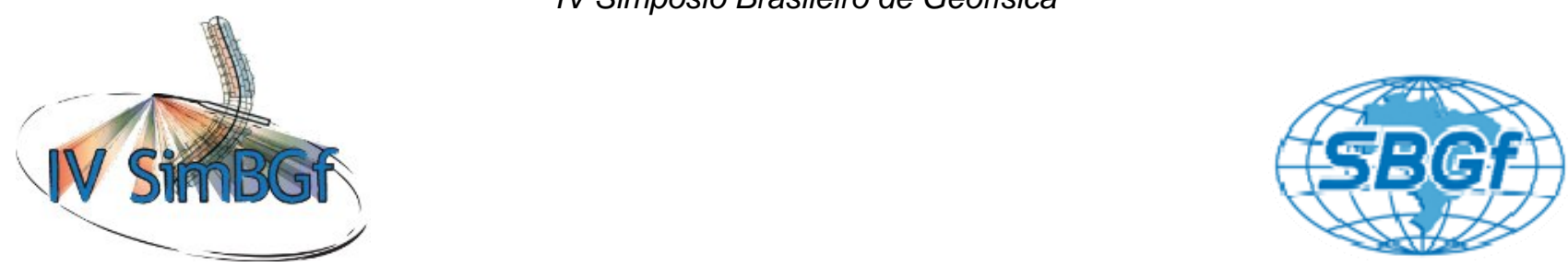

\title{
Metodologia para a Escolha do Algoritmo de Interpolação de Superfícies na Aplicação de Geoestatística Utilizadas no Modelo de Velocidade
}

Elaine Maria Lopes Loureiro, ANP

Anderson Batista Gomes, Schlumberger

Júlio Kosaka Oliveira, Schlumberger

Copyright 2010, SBGf - Sociedade Brasileira de Geofísica

Este texto foi preparado para a apresentação no IV Simpósio Brasileiro de Geofísica, Brasília, 14 a 17 de novembro de 2010. Seu conteúdo foi revisado pelo Comitê Técnico do IV SimBGf, mas não necessariamente representa a opinião da SBGf ou de seus associados. É proibida a reprodução total ou parcial deste material para propósitos comerciais sem prévia autorização da SBGf.

\section{Resumo}

Este estudo objetivou estabelecer uma metodologia eficiente para escolha do melhor algoritmo de interpolação para superfícies que será aplicada em modelos de velocidades num software de conversão. Nem sempre o software disponível na empresa possui todos os algoritmos mais utilizados no mercado, visto que muitos deles são patenteados.

Como se sabe, o algoritmo mais utilizado num caso de modelo de velocidade é o Kriging with External Drift (KED) ${ }^{2}$. Contudo neste caso foram testados Ordinary Kriging with Drift (OKWD), Inverse Distance (ID), Single Kriging (SK) e Ordinary Kriging (OK) disponíveis no LPM do GeoFrame (Schlumberger).

Empregando ferramentas estatísticas simples como resíduos e desvio padrão, foi possível mensurar qual o método mais eficiente e assim foi constatado que o Ordinary Kriging with Drift (OKWD) é o mais acurado dentre os estudados.

\section{Introdução}

A conversão tempo/profundidade é uma etapa importante da interpretação sísmica e hoje em dia é comum alguns geofísicos interpretarem diretamente no domínio da profundidade, sendo o cubo PSDM o atributo mais comumente usado.

Como o PSDM é um produto relativamente caro e demora um tempo significativo para ser enviado pela empresa de processamento, é habitual que intérprete gere sua própria conversão.

O modelo de velocidade empregado foi o de camada de bolo ("layer cake") feito pelo InDepth do GeoFrame (Schlumberger). A construção deste modelo necessita possuir os seguintes dados em um projeto:

a) Superfícies interpretadas em tempo;

b) Velocidades de cubos 3D ou linhas 2D;

c) $\mathrm{E}$ dados das profundidades (cotas) de topo e base das superfícies interpretadas (marcadores).

É imprescindível que esta metodologia seja aplicada numa área já conhecida. Neste a área testada é um reservatório já conhecido, do Golfo do México.

A conversão tempo e profundidade trata-se de um processo que tem três etapas a serem seguidas: Controle de Qualidade dos dados de entrada; gerar o modelo de velocidade e a conversão tempo para profundidade propriamente dita.

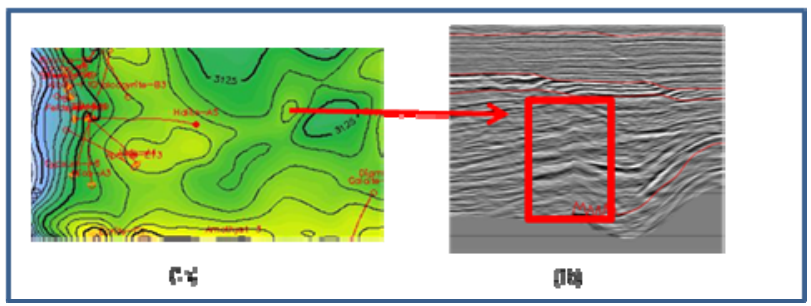

Figura 1 - A superfície convertida para profundidade (1a) usada no modelo possui ruído; a figura abaixo (2b) mostra o que este ruído causa na imagem da sísmica convertida.

Um desafio digno de consideração na conversão é a presença de ruído, que pode gerar problemas na imagem do cubo em profundidade. Este ruído é gerado na fase de construção do modelo, onde as superfícies usadas em tempo são convertidas para profundidade (figura 1).

Uma rápida solução para o problema seria a aplicação de uma suavização na superfície gerada para o modelo, porém a aplicação da geoestatística neste tipo de superfície torna-se mais interessante, visto que o variograma vai redistribuir as profundidades seguindo a tendência de dados obtidos no poço, ou seja, os dados mais acurados da área.

\section{Metodologia}

Visando testar os métodos, foi estabelecido o seguinte fluxo de trabalho:

a) Descartaram-se alguns poços na etapa da construção do modelo - neste estudo foram descartados 3 dos 36 poços;

b) Construiu-se o Modelo de Velocidade;

c) Aplicaram-se todos os algoritmos de disponíveis no software e geoestatísica - estabelecendo num variograma parâmetros como nuggets, 
range e sill - nas superfícies convertidas em Profundidade para o modelo de velocidade;

d) Criaram-se novos modelos de velocidade e foram injetadas estas superfícies geradas;

e) Converteram-se superfícies interpretadas em tempo para profundidade;

f) Calcularam-se os resíduos entre as superfícies geradas e os marcadores dos poços;

g) E os resíduos foram somados e feito uma média quadrática, calculando-se assim 0 desvio padrão.

Os resíduos foram calculados seguindo a seguinte fórmula ${ }^{1}$ :

$R=Y_{M}-Y_{S C}(1)$

Sendo:

$\mathrm{R}$ o resíduo (em metros)

$Y_{M}$ é a profundidade do marcadores (metros)

$Y_{S C}$ é a profundidade da superfície calculada (metros), 0

Com a fórmula 1 é possível calcular:

$\sigma=\sqrt{\frac{\sum R^{2}}{N-1}}$

Sendo:

$\sigma$ é o desvio padrão

$\mathrm{N}$ é o número de medições

E assim, o algoritmo que gerar o menor desvio padrão, será o melhor a ser empregado na conversão.

Este estudo utilizou quatro diferentes algoritmos disponíveis na ferramenta LPM pertencente ao GeoFrame: Ordinary Kriging with Drift (OKWD), Inverse Distance (ID), Single Kriging (SK) e Ordinary Kriging (OK). O primeiro algoritmo usa a Cokrigagem e os demais não.

Os demais algoritmos do LPM geraram superfícies que não tinham sentido geológico ou estrutural e por isso foram descartados.

\section{Resultados}

Os resultados são superfícies sem ruídos, eliminando picos que muitas vezes não tem sentido estrutural. A figura 2 mostra as comparações entre as superfícies antes e depois dos algoritmos serem aplicados. Verificouse que na parte norte da figura, há uma maior suavização.

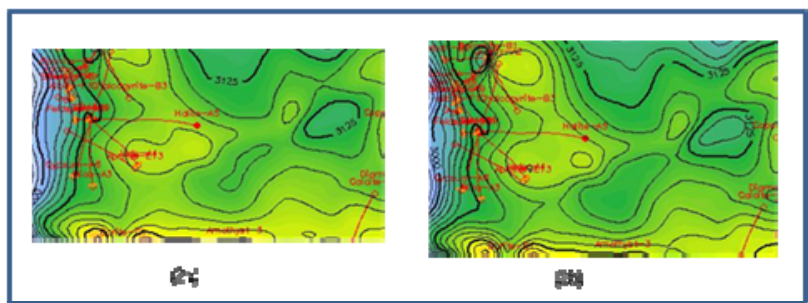

Figura 2 - A Figura 2a mostra a superfície sem suavização e a $2 b$ com o algoritmo Ordinary Kriging with Drift aplicado.

Esta suavização "inteligente" - isto é, empregada por uma geoestatística - pode possibilitar uma melhora na imagem da sísmica, resultando em um sinal mais contínuo como mostra na Figura 3.

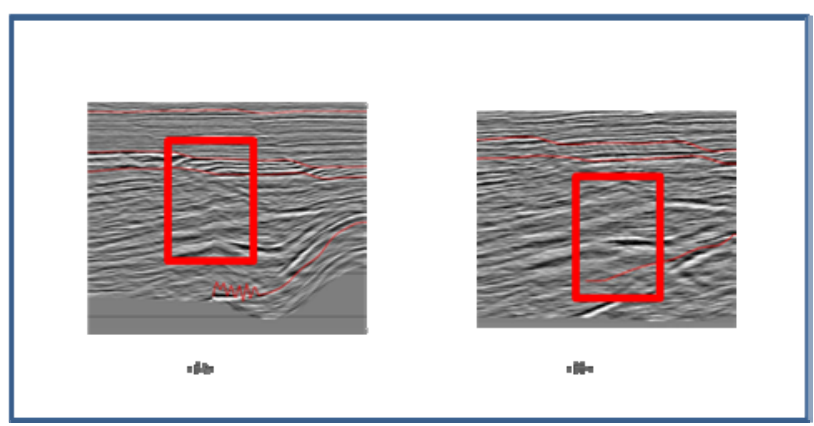

Figura 3 - A imagem da sísmica migrada convertida em profundidade gerada diretamente no software de conversão (3a) e a gerada usando superfícies em profundidade com geoestatística (3b). Pode-se constatar que a segunda imagem não possui ruído e por isso representa melhor os refletores.

$\mathrm{Na}$ comparação entre os métodos, foi percebido que o algoritmo Ordinary Kriging with Drift (OKWD) deu a melhor resposta. Ressalta-se que este algoritmo por usar a cokrigagem, foi necessária uma segunda variável para a interpolação, e para tal foi escolhida uma superfície em tempo. A tabela 1 a seguir mostra os resultados obtidos neste estudo.

\begin{tabular}{|l|r|}
\hline Algoritmos testados no GeoFrame & Desvio Padrão \\
\hline Ordinary Kriging with Drift (OKWD) & 21,02 \\
\hline Inverse Distance (ID) & 21,58 \\
\hline Ordinary Kriging (OK) & 22,06 \\
\hline Simple Kriging (SK) & 22,22 \\
\hline $\begin{array}{l}\text { Gerado pelo software (sem aplicação de } \\
\text { algoritmos) }\end{array}$ & 41,28 \\
\hline
\end{tabular}

Tabela 1 - Dados obtidos usando variados algoritmos de interpolação; o melhor resultado é o que possui o menor desvio padrão e neste caso foi o OKWD. 
A última linha da Tabela 1 mostra o valor do desvio padrão gerada pelo software InDepth que é o maior valor. Isto significa que é necessário aplicar a geoestatística para fazer a conversão, melhorando assim a sua acurácia.

\section{Discussão e Conclusões}

Este estudo, como foi dito anteriormente, objetivou estabelecer uma metodologia que ajudasse na escolha do melhor algoritmo a ser empregado na geoestatística em uma superfície a ser usada no modelo de velocidade.

Este fluxo de trabalho é útil para ajudar o intérprete que não tem no software disponível na sua empresa o algoritmo sugerido e mais utilizado no mercado, como é o caso do Kriging with External Drift (KED) ${ }^{2}$.

\section{Agradecimentos}

À Schlumberger por ter me dado a oportunidade de testar e validar este estudo.

\section{Referências}

(1) http://www.inf.furb.br/sias/saude/Textos/desvio padrao.htm

(2) http://ozelacademy.com/OJAS v1n1 9.pdf 